
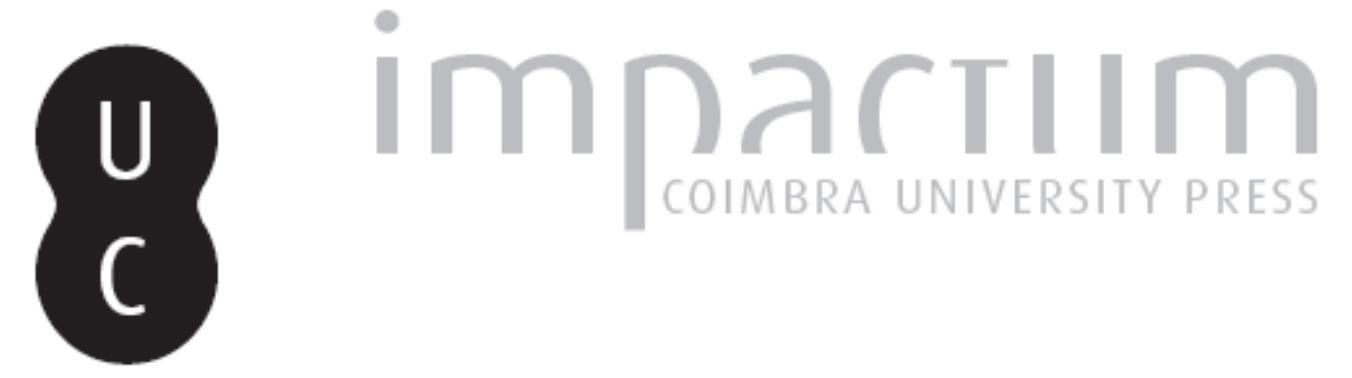
[Recensão a] Nestola, Paola (2016). San Giuseppe da Copertino: dall'estrema Puglia
al Portogallo (secc. XVII-XIX)
Autor(es):
Araújo, Ana Cristina
Publicado por: Imprensa da Universidade de Coimbra
URL
persistente:
URI:http://hdl.handle.net/10316.2/43343
DOI:
DOI:https://doi.org/10.14195/1645-2259_17_18

Accessed : $\quad$ 26-Apr-2023 09:05:34

A navegação consulta e descarregamento dos títulos inseridos nas Bibliotecas Digitais UC Digitalis, UC Pombalina e UC Impactum, pressupõem a aceitação plena e sem reservas dos Termos e Condições de Uso destas Bibliotecas Digitais, disponíveis em https://digitalis.uc.pt/pt-pt/termos.

Conforme exposto nos referidos Termos e Condições de Uso, o descarregamento de títulos de acesso restrito requer uma licença válida de autorização devendo o utilizador aceder ao(s) documento(s) a partir de um endereço de IP da instituição detentora da supramencionada licença.

Ao utilizador é apenas permitido o descarregamento para uso pessoal, pelo que o emprego do(s) título(s) descarregado(s) para outro fim, designadamente comercial, carece de autorização do respetivo autor ou editor da obra.

Na medida em que todas as obras da UC Digitalis se encontram protegidas pelo Código do Direito de Autor e Direitos Conexos e demais legislação aplicável, toda a cópia, parcial ou total, deste documento, nos casos em que é legalmente admitida, deverá conter ou fazer-se acompanhar por este aviso. 


\section{Nestola, Paola (2016). San Giuseppe da Copertino: dall'es- trema Puglia al Portogallo (secc. XVII-XIX). Lecce: Edizioni Grifo. 286 pp., ISBN 97888699404439}

A historiografia religiosa mais recente, partindo de fontes há muito conhecidas, documentais e iconográficas, tem vindo a explorar novas perspectivas de tratamento da santidade que apontam para a integração da dimensão antropológica da crença e do culto nas dinâmicas sociais, culturais e políticas das comunidades.

A obra de Paola Nestola, refletindo esta orientação historiográfica, convida à redescoberta da figura de frei Giuseppe Maria Desa (1603-1663), reatualiza a percepção histórica dos sinais prodigiosos atribuídos a San Giuseppe da Copertino (1753-1767) e desvenda os caminhos e os motivos de expansão do seu culto. A autora reuniu neste volume, editado com o apoio do Centro de História da Sociedade e da Cultura (CHSC), textos inéditos e artigos recentes publicados em revistas científicas e em atas de congressos. O livro é composto por uma esclarecedora introdução e por seis capítulos. Carece de uma sólida conclusão e de uma resenha bibliográfica final, instrumento de referenciação de indiscutível utilidade para o leitor. Anota-se ainda a ausência de um índice onomástico e toponímico de grande valia num estudo tão abrangente.

Distinguida pela Academia Portuguesa de História, em 2016, com o prémio História da Europa, a obra apresenta uma visão de conjunto do culto e da santidade de San Giuseppe da Copertino assente em três premissas fundamentais: a unidade da representação hagiográfica; o carácter polissémico da construção literária e memorial da santidade; e a função aglutinadora do culto.

De facto, a figura histórica do frade inicialmente venerado em Itália, na província da Terra de Otranto, ilustra, de forma muito singular, a relação dos homens e das mulheres com o sagrado na bacia do Mediterrâneo, durante a Época Moderna. A autora coloca a emulação hagiográfica e a ambição de santidade no seio da comunidade dos crentes. Mostra que a santidade fornece ideais de coesão e de identificação grupal e que na organização da fé, nas doutrinas e imagens do sobrenatural e de todos os aléns acessíveis e equilibrantes, a sociedade busca sinais e símbolos de imortalidade terrena e transcendente.

Portanto, o sentimento religioso, captado através de um estudo de caso, como aquele que se apresenta nesta obra, desempenha uma função essencial no processo de afirmação identitário da sociedade moderna. Ao aprofundar alguns traços colectivos de vivência da crença, a autora mostra que o fenómeno religioso não pode ser visto apenas como motivo de aspiração individual ou como matéria do domínio das igrejas. Está para além disso, ou seja, constitui um forte motivo de partilha e um veículo de comunicação imprescindível para a comunidade dos crentes. A este respeito evocamos, na linha dos trabalhos de Hans Belting, a per- 
sistência de certas imagens sacras e o que nelas os homens e mulheres projetam de si mesmos ao longo do tempo. Apesar de se conservarem nos altares das igrejas, as figuras sacras, com a sua nudez ou com as suas vestes, com as suas coroas ou sem elas, com atributos milagrosos ou simplesmente como intercessores celestes, habitam o imaginário coletivo e alimentam o silencioso diálogo da fé dos homens. Por mais profunda que seja a tentativa de compreensão da imagética religiosa, ficamos quase sempre aquém do que é nomeado, porque dificilmente acedemos ao interior das experiências de sofrimento e redenção que são narrativamente descritas e reescritas nos relatos hagiográficos, nas relações de milagres ou nas memórias que suportam os processos de beatificação e canonização.

Neste domínio específico, a memória que o franciscano Manuel Dâmaso publicou em Lisboa, em 1755, atesta, de modo inequívoco, o incomensurável pano de fundo humano subjacente a tantas e tão variadas intervenções prodigiosas atribuídas ao beato Giuseppe da Copertino.

Neste livro, é importante reter que a saga narrada tem um nome terreno e um nome celestial. Primeiro nasce Giuseppe Maria Desa (1603-1663), numa comunidade rural de Terra de Otranto, na diocese de Nardò, que abandona o século para professar na ordem de S. Francisco. Depois da sua morte ergue-se o nome do taumaturgo, mais tarde designado San Giuseppe da Copertino, de acordo com o processo de canonização. Neste processo, o primeiro antropónimo é cindido e é-lhe acrescentado um outro elemento de identificação toponímico, Copertino. Apesar da colação beatífica ter principiado no século XVII, só no decurso século XVIII, aquele membro da família franciscana passa a integrar, de pleno direito, a galeria hagiográfica da região italiana "delle Puglia". É beatificado em 1753, por decreto pontifício de Bento XIV, e a cerimónia solene de canonização ocorre em pleno século das Luzes, em Roma, no ano de 1767, sob o pontificado de Clemente XIII. Mas antes destas datas eram já rastreáveis, em Itália e em várias regiões da Europa, as virtudes milagrosas que justificaram a rápida expansão do culto de Giuseppe da Copertino.

Sobre este ângulo de análise, é minucioso o estudo que Paola Nestola faz da biografia do frade franciscano, pulicada por Domenico Bernini, em Roma, em 1722, e reeditada, em Veneza, em 1753, com o título Vita del servo di Dio fra Giuseppe da Copertino dell'Ordine dei Minori Conventuali. É também exaustivo o modo como analisa o processo de canonização e como contextualiza a iconografia de San Giusepe da Copertino, iluminando os seus múltiplos sentidos a partir da matriz franciscana e antoniana, de Santo António dos portugueses. Nesta linha, a sua proposta historiográfica contempla tanto a territorialidade originária da devoção ao santo taumaturgo italiano quanto a universalidade do seu culto, conforme explicita nos capítulos I, V e VIII do livro.

Em Portugal, é sensivelmente a partir de 1755, o ano do grande terramoto de Lisboa, que se inicia a difusão do culto do beato "José de Copertino". Mais do que a catástrofe, o facto de o cardial Conti, núncio apostólico em Lisboa, ter sido 
elevado ao pontificado com o título de Inocêncio XIII condicionou a boa aceitação daquele culto em terras lusas. Recorde-se que foi sob a égide deste pontífice que se acelerou o processo de beatificação de Giuseppe da Copertino. Dois anos depois de firmada a beatitude do antigo frade franciscano, a lógica de afirmação político-religiosa do novo pontificado de Bento XIV cruza-se com a necessidade de amparo e conforto espiritual dos fiéis depois do trágico terramoto de 1 de Novembro de 1755 . Estes factores, de natureza diversa, terão influído no processo de expansão da santidade Giuseppe da Copertino de Itália a Portugal.

É também interessante destacar a similitude que se estabelece entre a representação antropomórfica do novo santo e a tradição imagética antoniana em Portugal. Neste aspecto, Paola Nestola afirma que o culto se particulariza, em Portugal, recorrendo a traços fisionómicos e físicos que não causavam estranheza. Por outro lado, sabe-se que o santo era conhecido pelo seus voos e singulares estado de levitação, traços que, na atmosfera tardo-barroca portuguesa, dialogavam, perfeitamente, com a singularidade das experiências aerostáticas do famoso padre Bartolomeu de Gusmão, que tanto espanto e expectativa causaram na corte portuguesa. Curiosamente, na mesma altura, triunfa, com Giuseppe da Copertino, a antecipação místico-religiosa da possibilidade de elevação física dos corpos no ar, com o óbvio reconhecimento de Roma. São paralelismos interessantes.

No plano da representação social prevalece, a par do tópico dos voos, a proteção dada por San Giuseppe da Copertino aos estudantes, a outros voos, os do conhecimento - atributo este mais vincado nas sociedades do norte da Europa. Estas metáforas mais elitistas de narração da santidade conjugam-se, como demonstra a autora, com outra matriz mais interclassista de configurar a caução espiritual de San Giuseppe da Copertino, que, no imaginário católico, acudia, de igual modo, a ricos e pobres, a homens e mulheres e a plebeus, clérigos e nobres atingidos, indistintamente, pelos pecados da gula e da luxúria.

Com estes atributos e particularidades, a figura de Giuseppe da Copertino apresenta-se como uma magnífica construção cultural, afeita tanto às exigências de espetacularidade do Barroco, quanto à necessidade de inscrição do ensino $\mathrm{e}$ do estudo metódico de novos saberes nas margens da religiosidade católica, também ela em franca renovação na Época das Luzes. Toda a magnífica e rebuscada imagem do santo voador se presta a sucessivas leituras e reactualizações, sendo a que resulta da assunção de Giuseppe da Copertino como herói cívico na sua terra natal uma das mais surpreendentes. Estes e outros aspectos, analisados pela autora, com recurso a abundante documentação, conferem enorme abrangência a um livro instigante e inovador no contexto da história religiosa.

Ana Cristina Araújo

Faculdade de Letras da Universidade de Coimbra Centro de História da Sociedade e da Cultura araujo.anacris@sapo.pt 